\title{
Adoptive immunotherapy using autologous lymphocytes sensitized with HLA class I-matched allogeneic tumor cells
}

\author{
YOSHIYUKI YAMAGUCHI, AKIKO OHSHITA, KATSUJI HIRONAKA, RIKI OKITA, MAKOTO OKAWAKI, \\ KAZUO MATSUURA, ICHIRO NAGAMINE, TAKUHIRO IKEDA, MASAHIRO OHARA and JUN HIHARA \\ Department of Surgical Oncology, Research Institute for Radiation Biology and Medicine, \\ Hiroshima University, Kasumi 1-2-3, Minami-ku, Hiroshima 734-8553, Japan
}

Received January 18, 2006; Accepted March 2, 2006

\begin{abstract}
A 29-year-old female breast cancer patient with multiple bone metastases (HLA-A2) was treated with adoptive transfer using autologous peripheral blood mononuclear cells (PBMCs) activated with the HLA-A2-matched allogeneic GC022588 gastric cancer cell line and interleukin-2 plus an immobilized anti-CD3 antibody culture system. The relief of bone pain in parallel with a decrease of serum carcinoembryonic antigen levels was obtained just after the administration of GC022588-activated effector lymphocytes, and a good quality of life was accomplished for 4 months. The GC022588-activated effector lymphocytes included $44 \% \mathrm{CD}^{+}$, $77 \% \mathrm{CD}^{+}$, and $26 \% \mathrm{CD}^{+} \mathrm{CD} 8^{+}$phenotypes, and expressed $25 \%$ killing activity against GC022588 stimulator cells at an $\mathrm{E} / \mathrm{T}$ ratio of 50:1. T cell receptor (TCR) usage analysis for the effector cells showed oligoclonal expression of TCRVB1, 3,9 , and 11 , especially TCRVß5.2, 12,13.1 and 17, and their killing activity was significantly inhibited in the presence of anti-TCR $\alpha \beta$ antibody and anti-TCRVß12 antibody. SSCP analysis revealed clonotypic bands of TCRVB12. These results suggest that shared antigens exist between breast and gastric adenocarcinomas. Allogeneic tumor cells can stimulate PBMCs to generate effector cells with selected TCRCDR3 usages that recognize tumor antigens. These effector lymphocytes may be good candidates for the adoptive immunotherapy of cancer.
\end{abstract}

Correspondence to: Dr Yoshiyuki Yamaguchi, Department of Surgical Oncology, Research Institute for Radiation Biology and Medicine, Hiroshima University, Kasumi 1-2-3, Minami-Ku, Hiroshima 734-8553, Japan

E-mail: shogo@hiroshima-u.ac.jp

Abbreviations: AIT, adoptive immunotherapy; CD, cluster of differentiation; CDR, complementarity determining region; CEA, carcinoembryonic antigen; CTL, cytotoxic T lymphocyte; DCs, dendritic cells; FITC, fluorescein isothiocyanate; HLA, human leukocyte antigen; IL, interleukin; LAK, lymphokine-activated killer; MLTC, mixed lymphocyte tumor culture; PBMCs, peripheral blood mononuclear cells; PE, phycoerythrin; RNA, ribonuclease; SSCP, single-strand conformational polymorphism; TCR, T cell receptor; TILs, tumor-infiltrating lymphocytes

Key words: adoptive immunotherapy, shared antigen, in vitro sensitization, $\mathrm{T}$ cell receptor

\section{Introduction}

Discovery and molecular cloning of the crucial lymphocyte growth factor interleukin-2 (IL-2) has facilitated the clinical application of autologous peripheral blood mononuclear cells (PBMCs) activated in vitro with IL-2 $(1,2)$. Adoptive immunotherapy (AIT) using lymphokine-activated killer (LAK) cells (1) has demonstrated limited clinical efficacy against renal cell carcinoma, malignant melanoma, and nonHodgkin's lymphoma. The unfavorable results of AIT using LAK cells has indicated the necessity of using effector cells that are more cytotoxic and specific for target cells (2). Therefore, AIT using tumor infiltrating lymphocytes (TILs) has been aimed at increasing the lymphocyte homing capacity and specificity for tumor cells (2). AIT using TILs, however, has shown several clinical problems, including a limited number of patients from whom TILs can be obtained, and a limited amount of TILs that can be obtained from those patients. The therapy therefore requires a great deal of effort, special equipment, and a technique for the expansion of TILs $(2,3)$. Although there have been promising reports on the use of AIT using LAK cells or TILs for lung cancer (4), liver cancer (5), ovarian cancer (6) in an adjuvant setting, and for melanoma in combination with lymphodepleting chemotherapy (7), the development of more practical, convenient, and potent effector cells enhances the activity of AIT for cancer.

To overcome the above-mentioned limitations, researchers have focused on in vitro sensitization of PBMCs to generate cytotoxic $\mathrm{T}$ lymphocytes (CTLs) using a professional antigenpresenting cell, dendritic cells (DCs), together with tumor cells/antigens. We previously described the AIT trial using antigen peptide-pulsed DC-activated killer cells (8). This approach may be insufficient for the heterogenous nature of tumor antigens (9). Considering the heterogeneity of tumor antigens, much interest has been focused on in vitro sensitization of PBMCs using DCs, which are pulsed with tumor cell lysate (10), fused with tumor cells (11), or introduced with tumor RNA (12). More simply, in vitro sensitization of PBMCs using whole tumor cells alone of autologous $(13,14)$ or allogeneic $(15,16)$ origin has also been investigated.

In this manuscript, we report on a breast cancer patient with multiple bone metastasis who was effectively treated with adoptive immunotherapy using autologous lymphocytes 


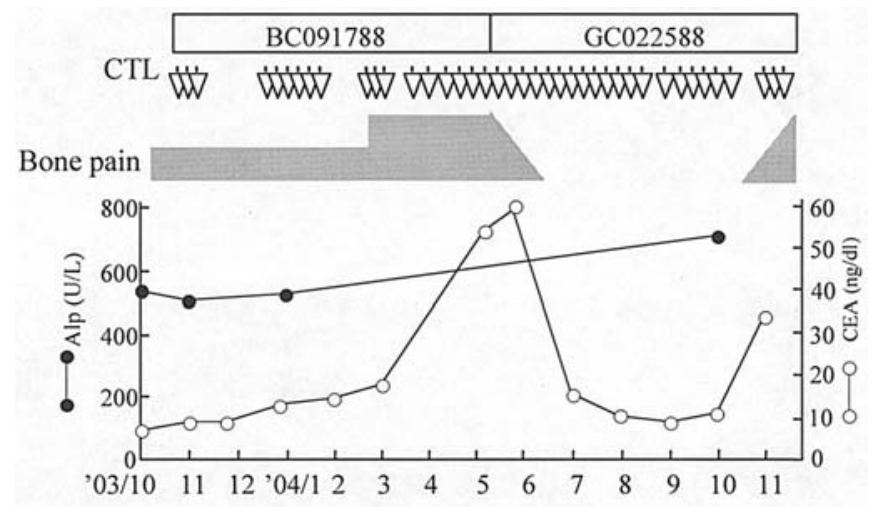

Time course

Figure 1. Clinical course and changes of tumor markers. A 29-year-old female breast cancer patient with multiple bone metastasis (HLA-A2,33, B51,44, and DR2,6 ) was treated with adoptive transfer of allogenic tumorsensitized autologous lymphocytes in an outpatient clinic. Treatment schedule, changes in bone pain and serum levels of tumor markers are presented.

activated with allogeneic whole tumor cells. Moreover, T cell receptor (TCR) analysis responsible for the killing activity of the effector lymphocytes was further performed.

\section{Materials and methods}

Cell lines. The human GC022588 gastric cancer cell line and human BC091788 breast cancer cell line (17) were kindly provided by Professor S. Fujimoto, Kochi Medical University, and transferred twice a week in RPMI-1640 medium (Gibco) supplemented with 5\% fetal bovine serum (FBS), 2 mM 1glutamine, $100 \mathrm{U} / \mathrm{ml}$ penicillin, and $100 \mu \mathrm{g} / \mathrm{ml}$ streptomycin. GC022588 cells were HLA class I-positive, class II-negative, CD80-negative and CD86-negative, and BC091788 cells were HLA class I-negative, class II-negative, CD80-negative and CD86-negative, as determined by flow cytometry. K562 cells (HLA null) from an erythroleucemia cell line were cultured in the same medium and used as targets for cytotoxicity assay.

Tumor sensitization and expansion of effector lymphocytes. PBMCs were collected from a breast cancer patient with bone metastasis (HLA-A2,33, B51,44, and DR2,6) by a standard density centrifugation method. BC091788 cells (HLA-A24,33, B12,13, and C1,3) and GC022588 cells (HLA-A2,24, B35,55, and $\mathrm{C} 1,3)$ were pre-treated with $50 \mu \mathrm{g} / \mathrm{ml}$ of mitomycin-C (MMC; Kyowa Hakkou Pharmaceutical Co. Ltd., Tokyo) for $2 \mathrm{~h}$ at $37^{\circ} \mathrm{C}$, and washed four times with RPMI-1640 medium. PBMCs $\left(10^{6} / \mathrm{ml}\right)$ were sensitized with MMC-treated tumor cells $\left(5 \times 10^{4} / \mathrm{ml}\right)$ in $1 \mathrm{ml}$ of RPMI-1640 medium containing $2 \%$ autologous serum in a round-bottomed tube for 5-7 days at $37^{\circ} \mathrm{C}$. Cells were washed three times with RPMI-1640 medium and further expanded on an anti-CD3 antibody-coated flask (Janssen-Kyowa, Tokyo, Japan) in the presence of $80 \mathrm{U} / \mathrm{ml}$ IL-2 (Shionogi, Osaka, Japan) (IL-2/CD3 system) $(16,18)$. On day 14 , the cells were harvested and subjected to adoptive immunotherapy and further experiments.

Antibody and flow cytometry. Effector cells expanded as above were stained with antibodies, washed, and then analyzed



Figure 2. Phenotypic analysis of tumor-sensitized effector cells. Effector cells were generated by in vitro sensitization using allogeneic GC022588 gastric cancer cells and further expanded with an IL-2/CD3 culture system. Cells were stained with antibodies and analyzed on Cytoron.

on Cytoron (Becton-Dickinson, San Diego, CA). The antibodies were anti-class I, anti-class II, anti-CD80, and anti-CD86 for tumor cells, and anti-CD3, anti-CD4 and anti-CD8 for effector cells. All antibodies were purchased from Becton-Dickinson.

Cytotoxicity assay. To examine the cytotoxic activity of the tumor-sensitized effector cells, a conventional 4-h ${ }^{51} \mathrm{Cr}$ release assay was performed using GC022588, BC091788 and K562 cells as targets. The target cells were labeled with ${ }^{51} \mathrm{Cr}(100 \mu \mathrm{Ci})$ for $2 \mathrm{~h}$, washed three times, and plated onto round-bottomed, 96-well microtiter plates at a concentration of $1 \times 10^{4}$ cells $/ 0.1 \mathrm{ml}$. The expanded effector cells were added over the target cells at various concentrations in a final volume of $0.2 \mathrm{ml}$. After 4 -h incubation at $37^{\circ} \mathrm{C}$, the release of ${ }^{51} \mathrm{Cr}$ in the supernatant was measured by an automated gamma counter (Aloka, Tokyo, Japan). The mean percentage of the specific lysis of triplicate wells was calculated using the following formula: cytotoxic activity $(\%)=$ [experimental release $(\mathrm{cpm})$ - spontaneous release $(\mathrm{cpm})] /[$ maximal release (cpm) - spontaneous release $(\mathrm{cpm})] \mathrm{x} 100$. The spontaneous release was generally up to $15 \%$ of the maximum release in our experiments. To explore the T-cell receptors responsible for the cytotoxic mechanism, the effector cells were incubated for $1 \mathrm{~h}$ at $4^{\circ} \mathrm{C}$ with $10 \mu \mathrm{g} / \mathrm{ml}$ of anti-TCR $\alpha \beta$, and antiTCRVB5.2, 12, and 17 antibodies (Ortho Diagnostic System, Raritan, NJ) and then subjected to cytotoxicity assay.

RT-PCR-Southern blot analysis of the TCRV $\beta$ gene. Total RNA was extracted from $5 \times 10^{5}$ of PBMCs and effector cells, and reverse-transcribed with a random hexamer as described previously $(19,20)$. Aliquots of the cDNA were amplified by PCR in separate tubes, using Vß-specific oligonucleotides as forward primers and $\mathrm{C}$, reverse primer on a DNA thermal cycler (Perking-Elmer, Norwalk, CT). The amplified DNA was confirmed by Southern blot analysis using a $\mathrm{C} B$ probe with luminol reaction.

Diagnostic single-strand conformation polymorphism. To detect the clonotype of complementarity determining region (CDR) 3 in the PCR product of each TCRVß band, the diagnostic single-strand conformational polymorphism (SSCP) technique was performed $(19,20)$. In brief, $5 \mu 1$ of the 




Figure 3. Cytotoxic activity of effector cells stimulated with tumor cells Effector cells were generated by in vitro sensitization using allogeneic cancer cells as indicated, and further expanded with an IL-2/CD3 culture system. Cytotoxic activity was determined using a ${ }^{51} \mathrm{Cr}$-releasing assay. *Significant difference of $\mathrm{p}<0.05$.

asymmetric PCR product was mixed with $5 \mu 1$ of $95 \%$ formamide containing xylene cyanol and bromophenol blue, heated at $95^{\circ} \mathrm{C}$ for $5 \mathrm{~min}$, cooled on ice, and then loaded onto a $10 \%$ acrylamide gel. This was run at $100 \mathrm{~V}$ for $4 \mathrm{~h}$ in a cold room $\left(4^{\circ} \mathrm{C}\right)$. The gel was then silver-stained (Silver Stain Plus; BioRad, Hercules, CA, USA).

Statistical analysis. Statistical evaluations for experimental values were analyzed using the Student's $t$-test.

\section{Results}

Clinical course and changes of tumor markers. A 29-yearold female breast cancer patient with multiple bone metastases (HLA-A2,33, B51,44, and DR2,6) was consulted in our outpatient clinic on December 2004. Standard chemotherapy, including doxorubicin, cyclophosphamide, 5-fluorouracil, vinorelbine, taxanes, and hormone therapies, had already failed to inhibit the progression of bone metastases with pain. After sufficient written informed consent, AIT on an outpatient basis using autologous lymphocytes activated with allogenic tumor sensitization was planned. First, the patient's PBMCs were stimulated in vitro with the BC091788 breast cancer cell line, which had HLA-A33-matched alleles. A total number of $5.3 \times 10^{10}$ BC091788-activated autologous lymphocytes were transferred intravenously. However, bone pain increased, as well as serum carcinoembryonic antigen (CEA) levels (Fig. 1). We changed tumor cells from the BC091788 to HLA-A2-matched GC022588 gastric cancer cells to sensitize the patient's PBMCs. Autologous lymphocytes activated with GC022588 were expanded with an IL-2/CD3 culture system and transferred intravenously every week. A total cell number of $8.4 \times 10^{10}$ cells were administered. The relief of bone pain in parallel with a decrease of serum CEA levels was obtained

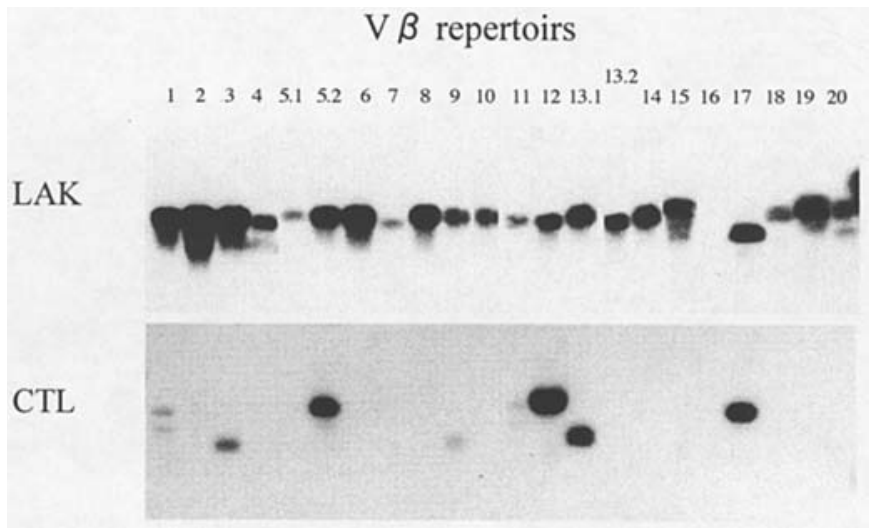

Figure 4. Analysis for TCRVß gene usage of LAK cells and effector cells stimulated with allogeneic tumor cells. mRNA was extracted from LAK cells or effector cells, and RT-PCR-Southern blot analysis and hybridization were performed to analyze TCRVß gene usage.

just after the administration of GC022588-activated autologous lymphocytes, and a good quality of life was accomplished for 4 months.

Phenotypic analysis for effector cells. Phenotypic analysis for GC022588-activated autologous lymphocytes was performed during a positive clinical response of AIT (Fig. 2). GC022588activated lymphocytes showed $44 \% \mathrm{CD}^{+}$and $77 \% \mathrm{CD}^{+}$ phenotypes, including $26 \% \mathrm{CD} 4{ }^{+} \mathrm{CD}^{+}$cells.

Cytotoxic activity of effector cells activated with GC022588 cells. The cytotoxic activity of effector cells was assessed during a positive clinical response of AIT (Fig. 3). Effector cells activated with BC091788 cells killed $<10 \%$ of BC091788 target cells at an E/T ratio of 50:1. Effector cells activated with GC022588 cells showed $25 \%$ killing activity against GC022588 cells at an E/T ratio of 50:1. There was a significant difference between the killing activity of effector cells against BC091788 and GC022588 cells $(\mathrm{p}<0.05)$. However, the effector cells did not lyse K562 target cells.

Southern blot analysis and hybridization for TCRs in effector cells activated with GC022588 cells. TCR usage analysis was performed using Southern blot analysis and hybridization on PCR products of GC022588-activated effector cells amplified by primers specific for TCRs (Fig. 4). LAK cells, which were stimulated only with the IL-2/CD3 culture system without tumor sensitization, showed a diverse expression of TCRs. On the other hand, effector cells activated with GC022588 cells had an oligoclonal expression of TCRVß1, 3, 9 and 11, especially TCRVß5.2, 12, 13.1 and 17.

Analysis of the TCR responsible for tumor killing activity. Cytotoxicity assay was performed with blocking analysis using antibodies recognizing TCRVß molecules to determine TCRs responsible for the cytotoxic activity of GC022588activated effector cells (Fig. 5). The GC022588-activated effector cells showed $26 \%$ killing activity against GC022588 target cells, which was not affected by the control Ig. The killing activity of GC022588-activated effector cells was significantly inhibited in the presence of anti-TCR $\alpha \beta$ antibody 




Figure 5. Analysis of the TCR responsible for tumor killing activity. Cytotoxicity assay for GC022588-sensitized effector cells was performed in the presence of anti-TCR antibodies as indicated. Significant differences of ${ }^{*} \mathrm{p}<0.05$ and ${ }^{* *} \mathrm{p}<0.01$

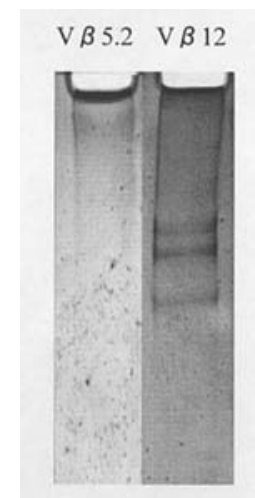

Figure 6. SSCP analysis for TCRVB5.2 and 12 genes of GC022588-activated effector cells. DNA fragments of TCR genes obtained from GC022588sensitized effector cells by RT-PCR amplification were subjected to SSCP analysis to determine clonotypic expression of TCRCDR3.

$(11 \%, \mathrm{p}<0.05)$ as well as the anti-TCRVß12 antibody $(10 \%$, $\mathrm{p}<0.01)$. However, anti-TCRVB5.2 or 17 antibodies failed to abrogate the killing activity of GC022588-activated effector cells.

SSCP analysis for TCRVß genes from CTLs. SSCP analysis was performed to determine the clonotypic expression of TCRVB5.2 and 12 of GC022588-activated effector cells (Fig. 6). The analysis on TCRVB5.2 showed a smear pattern of DNA fragments. However, DNA fragments of TCRVB12 demonstrated a pair of clonotypic bands at $247 \mathrm{bp}$.

\section{Discussion}

In melanoma studies, it has been demonstrated that shared antigens exist among tumor cells (21), which is presented in the context of HLA class I (22) and class II molecules (23). In the present study, we demonstrated the existence of shared antigen(s) between breast and gastric adenocarcinomas, as a breast cancer patient with painful multiple bone metastases was successfully treated with allogeneic gastric cancer cellsensitized autologous killer cells activated with the IL-2/CD3 culture system. The molecular-level understanding of such tumor-shared antigens has allowed the use of HLA-matched allogeneic tumor cells as tumor sensitization for CTL generation (15). This technique can facilitate in vitro CTL generation by eliminating the need for autologous tumor cells.

Using an in vitro tumor sensitization technique for adoptive immunotherapy of cancer, Soda et al reported that in vitro CTL induction is difficult in patients with advanced cancer, and the expression of HLA class I and co-stimulatory CD80 molecules is essentially required on tumor cells for successful CTL induction (14). In our investigation, GC022588 gastric cancer cells expressed HLA class I and successfully stimulated autologous PBMCs to generate effector lymphocytes. On the other hand, BC091788 breast cancer cells did not express HLA class I molecules nor generated effective killer lymphocytes, indicating the possible requirement of HLA class I expression on stimulator tumor cells. However, GC022588 cells did not express CD80 or CD86 co-stimulatory molecules. Takenoyama et al demonstrated that CTLs against human lung cancer cells are difficult to induce by a conventional method using tumor cell stimulation, although CD80 gene transduction into tumor cells makes them immunogenic (24). Schendel et al also described the importance of CD80 expression on allogeneic tumor cells to elucidate tumor antigen-specific CLT responses (15). The genetic modification technique for tumor cells may be a promising strategy to promote adoptive immunotherapy of cancer using effector lymphocytes activated with a mixed tumor cell-lymphocyte reaction, as well as the use of dendritic cells modified with tumor antigens, lysates, and RNAs $(8,10-12)$.

We attempted to analyze the TCRVß gene usage of GC022588-activated effector lymphocytes, and found an oligoclonal expression of TCRVß gene usage including the TCRVß12 gene. Of note, a blocking assay using the antiTCRVB12 antibody demonstrated a significant reduction of cytotoxic activity of the effector cells, indicating that the usage of TCRVß12 was responsible for the cytotoxity. Moreover, a pair of clonotypic bands was detected by an SSCP analysis in the TCRVß12 gene fragments, suggesting that $\mathrm{T}$ cells expressing tumor antigen-reactive $\mathrm{CDR} 3$ regions were selectively expanded by GC022588 cell stimulation. Previously, we and others demonstrated a TCRVß12CDR3 responsible for recognizing an important tumor antigen, CEA $(20,25)$. GC022588 gastric cancer cells expressed the CEA antigen (data not shown), and serum CEA levels of the patient drastically decreased in parallel with the relief of bone pain after adoptive transfer of GC022588-activated effector lymphocytes, indicating that the GC022588-activated effector lymphocytes may have worked with recognizing CEA, and the clonotypic expression of TCRVß12 shown here may also indicate that CDR3 is reactive with CEA. The detection of TCRs responsible for tumor antigen recognition is an important issue to address. Xue et al demonstrated that the introduction of TCR genes into CD8(+) and CD4(+) lymphocytes provides an opportunity to use the same TCR specificity to produce antigen-specific killer and helper T lymphocytes, and TCR gene therapy provides an attractive strategy to develop antigen-specific immunotherapy with autologous lymphocytes as a genetic treatment option, which does not require the immunocompetence of patients (26). We are currently investigating the sequence of the TCRVB12 gene for a possible TCR gene therapy trial in the future. 


\section{References}

1. Rosenberg SA, Lotze MT, Muul LM, Leitman S, Chang AE, Ettinghausen SE, Matory YL, Skibber JM, Shiloni E and Vetto JT: Observations on the systemic administration of autologous lymphokine-activated killer cells and recombinant interleukin-2 to patients with metastatic cancer. N Engl J Med 313: 1485-1492, 1985.

2. Rosenberg SA, Spiess P and Lafreniere R: A new approach to the adoptive immunotherapy of cancer with tumor-infiltrating lymphocytes. Science 233: 1318-1321, 1986.

3. Yamaguchi Y, Ohta K, Shimizu K, Minami K, Noma K, Hihara J and Toge T: Generation of cytotoxic effector lymphocytes by MLTC using tumor cells genetically modified to secrete interleukin-2. Anticancer Res 21: 669-677, 2001.

4. Kimura $\mathrm{H}$ and Yamaguchi Y: A phase III randomized study of interleukin-2 lymphokine-activated killer cell immunotherapy combined with chemotherapy or radiotherapy after curative or noncurative resection of primary lung carcinoma. Cancer 80: 42-49, 1997.

5. Takayama T, Sekine T, Makuuchi M, Yamasaki S, Kosuge T, Yamamoto J, Shimada K, Sakamoto M, Hirohashi S, Ohashi Y and Kakizoe T: Adoptive immunotherapy to lower postsurgical recurrence rates of hepatocellular carcinoma: a randomised trial. Lancet 356: 802-807, 2000.

6. Merogi AJ, Marrogi AJ, Ramesh R, Robinson WR, Fermin CD and Freeman SM: Tumor-host interaction: analysis of cytokines, growth factors, and tumor-infiltrating lymphocytes in ovarian carcinomas. Hum Pathol 28: 321-331, 1997.

7. Dudley ME, Wunderlich JR, Yang JC, Sherry RM, Topalian SL, Restifo NP, Royal RE, Kammula U, White DE, Mavroukakis SA, Rogers LJ, Gracia GJ, Jones SA, Mangiameli DP, Pelletier MM, Gea-Banacloche J, Robinson MR, Berman DM, Filie AC, Abati A and Rosenberg SA: Adoptive cell transfer therapy following non-myeloablative but lymphodepleting chemotherapy for the treatment of patients with refractory metastatic melanoma. J Clin Oncol 23: 2346-2357, 2005.

8. Yamaguchi Y, Ohta K, Kawabuchi Y, Ohshita A, Okita R, Okawaki M, Hironaka K, Matsuura K and Toge T: Feasibility study of adoptive immunotherapy for metastatic lung tumors using peptide-pulsed dendritic cell-activated killer (PDAK) cells. Anticancer Res 25: 2407-2415, 2005.

9. Chen Y, Wu K, Guo C, Liu C, Han S, Lin T, Ning X, Shi R, Shi Y and Fan D: A novel DNA vaccine containing four mimicry epitopes for gastric cancer. Cancer Biol Ther 4: 308-312, 2005.

10. Suresh K, Fraser G, Scheid E, Leber B, Gauldie J and Foley R: Generation of in vitro B-CLL specific HLA class I restricted CTL responses using autologous dendritic cells pulsed with necrotic tumor lysate. Leuk Lymphoma 47: 297-306, 2006.

11. Guo G, Chen S, Zhang J, Luo L, Yu J, Dong H, Xu H, Su Z and $\mathrm{Wu} \mathrm{L}$ : Antitumor activity of a fusion of esophageal carcinoma cells with dendritic cells derived from cord blood. Vaccine 23: 5225-5230, 2005.

12. Ohshita A, Yamaguchi Y, Minami K, Hihara J and Toge T: Generation of tumor-reactive effector lymphocytes using tumor RNA-introduced dendritic cells in gastric cancer patients. Int J Oncol (In press).

13. Aruga A, Yamauchi K, Takasaki K, Furukawa T and Hanyu F: Induction of autologous tumor-specific cytotoxic $\mathrm{T}$ cells in patients with liver cancer. Characterizations and clinical utilization. Int J Cancer 49: 19-24, 1991.
14. Soda H, Koda K, Yasutomi J, Oda K, Takiguchi N, Saito N and Nakajima N: Adoptive immunotherapy for advanced cancer patients using in vitro-activated cytotoxic T lymphocytes. J Surg Oncol 72: 211-217, 1999

15. Schendel DJ, Frankenberger B, Jantzer P, Cayeux S, Nobetaner E, Willimsky G, Maget B, Pohla $\mathrm{H}$ and Blankenstein T: Expression of B7.1 (CD80) in a renal cell carcinoma line allows expansion of tumor-associated cytotoxic T lymphocytes in the presence of an alloresponse. Gene Ther 7: 2007-2014, 2000.

16. Yamaguchi Y, Ohta K, Shimizu K, Minami K, Noma K, Hihara J and Toge T: Generation of cytotoxic effector lymphocytes by MLTC using tumor cells genetically modified to secrete interleukin-2. Anticancer Res 21: 669-677, 2001.

17. Imada $\mathrm{M}$ and Fujimoto $\mathrm{S}$ : $\mathrm{T}$ cell response to embryonal carcinoma F9 cells: induction and characterization of $\mathrm{T}$ cell receptor alpha beta $^{+}$double-negative cytotoxic T lymphocytes. Jpn J Cancer Res 84: 58-64, 1993.

18. Sekine T, Shiraiwa H, Yamazaki T, Tobisu K and Kakizoe T: A feasible method for expansion of peripheral blood lymphocytes by culture with immobilized anti-CD3 monoclonal antibody and interleukin-2 for use in adoptive immunotherapy of cancer patients. Biomed Pharmacother 47: 73-78, 1993.

19. Miyahara E, Yamaguchi Y, Minami K, Hihara J, Noma K, Toge T, Takafuta $T$ and Fujimura $K$ : T-cell receptor Vß gene usage of human cytotoxic T-cell clones obtained from gastric cancer patients. Anticancer Res 19: 2057-2066, 1999.

20. Ohta K, Yamaguchi Y, Shimizu K, Miyahara E and Toge T: Novel system for generation cytotoxic effector lymphocytes using carcinoembryonic antigen (CEA) peptide and cultured dendritic cells. Anticancer Res 22: 2597-2606, 2002.

21. Huang LQ, Brasseur F, Serrano A, De Plaen E, Boon T, Van der Bruggen $\mathrm{P}$ and Van Pel A: Cytolytic T lymphocytes recognize an antigen encoded by MAGE-A10 on a human melanoma. J Immunol 162: 6849-6854, 1999.

22. Kawakami Y, Dang N, Wang X, Tupesis J, Robbins PF, Wang RF, Wunderlich JR, Yannelli JR and Rosenberg SA: Recognition of shared melanoma antigens in association with major HLA-A alleles by tumor infiltrating T lymphocytes from 123 patients with melanoma. J Immunother 23: 17-27, 2000.

23. Chiari R, Hames G, Stroobant V, Texier C, Maillere B, Boon T and Coulie PG: Identification of a tumor-specific shared antigen derived from an Eph receptor and presented to CD4 T cells on HLA class II molecules. Cancer Res 60: 4855-4863, 2000.

24. Takenoyama M, Yoshino I, Eifuku R, So T, Imahayashi S, Sugaya M, Yasuda M, Inoue M, Ichiyoshi Y, Osaki T, Nagashima A, Nomoto K and Yasumoto K: Successful induction of tumor-specific cytotoxic T lymphocytes from patients with non-small cell lung cancer using CD80-transfected autologous tumor cells. Jpn J Cancer Res 92: 309-315, 2001.

25. Alters SE, Gadea JR, Sorich M, O'Donoghue G, Talib S and Philip R: Dendritic cells pulsed with CEA peptide induce CEAspecific CTL with restricted TCR repertoire. J Immunother 21: $17-26,1998$.

26. Xue S, Gillmore R, Downs A, Tsallios A, Holler A, Gao L, Wong V, Morris E and Stauss HJ: Exploiting T cell receptor genes for cancer immunotherapy. Clin Exp Immunol 139: 167-172, 2005. 